\title{
Assédio moral no trabalho e estratégias organizacionais no contexto do Instituto Federal Catarinense
}

\section{Moral harassment at work and organizational strategies in the context of Instituto Federal Catarinense}

\author{
Israel Vasconselos Cardoso MSc. em Administração pela Universidade do Vale do Itajaí (UNIVALI). Brasil. \\ israel.vasconselos@gmail.com \\ Micheline Ramos de Oliveira Dra. em Antropologia Social pela Universidade Federal de Santa Catarina (UFSC). Brasil. \\ micheantr@hotmail.com \\ Flávio Ramos Dr. em Sociologia Política pela Universidade Federal de Santa Catarina (UFSC). Brasil. \\ flauni10@gmail.com
}

\begin{abstract}
RESUMO
O assédio moral no trabalho é um tema contemporâneo que vem ganhando importância crescente na sociedade. Em síntese, pode ser caracterizado como condutas inadequadas no local de trabalho que trazem graves consequências para o indivíduo em todas as suas dimensões, para as organizações e para a sociedade. Nesse contexto, o objetivo geral desta pesquisa é perscrutar as estratégias de gestão no Instituto Federal Catarinense para conscientização e prevenção do assédio moral no âmbito educacional e administrativo. Esta pesquisa é de natureza qualitativa, orientada pelo paradigma interpretativo, e faz parte do grupo das pesquisas exploratórias. Com relação às estratégias de investigação, optou-se pela pesquisa bibliográfica, documental e estudo de caso. A presente pesquisa foi desenvolvida no Instituto Federal Catarinense, e a pesquisa documental foi realizada entre 2014 e 2018, por meio do acesso às informações e documentos publicados nas páginas da instituição. As entrevistas presenciais foram realizadas com oito servidores da instituição no ano de 2019 e os dados e informações obtidos foram tratados utilizando-se a análise de conteúdo de Bardin. Após análise dos dados ficou evidenciado que as estratégias de gestão do assédio moral no Instituto Federal Catarinense são desenvolvidas especialmente pela Corregedoria, pela Comissão de Ética e pela Ouvidoria. Constatou-se que, apesar dos avanços identificados pelos entrevistados, é necessário o desenvolvimento de uma política de capacitação sobre o assédio moral no trabalho para todos os servidores da instituição.
\end{abstract}

Palavras-chave: Assédio moral no trabalho. Instituto Federal Catarinense. Estratégias de gestão.

\begin{abstract}
Moral harassment in the workplace is a contemporary issue which is gaining increasing importance in society. Briefly, it can be defined as inappropriate behavior at work which can lead to serious consequences for the individual, for organizations and for society as a whole. Within this context, the aim of this research is to examine the management strategies at Instituto Federal Catarinense to raise awareness regarding moral harassment and prevent its occurrence in educational and administrative spheres. This research is qualitative, guided by the interpretive paradigm, and is part of the group of exploratory research. The investigation strategies comprised bibliographic, documentary research and case study methods. This research was developed at Instituto Federal Catarinense. The documentary research was carried out between 2014 and 2018 through access to information and documents published on the institution's pages. The in-person interviews were conducted with eight employees of the institution in 2019; the data and information obtained were examined using Bardin's content analysis. Analysis of the data showed that the management strategies used to deal with moral harassment at Instituto Federal Catarinense are specially developed by the Internal Affairs, the Ethics Committee and the Ombudsman. It was concluded that, despite improvements identified by the interviewees, it is still necessary to further develop an awareness-raising policy on moral harassment in the workplace for all employees of the institution.
\end{abstract}

Keywords: Moral harassment at work. Instituto Federal Catarinense. Management strategies. 


\section{INTRODUÇÃO}

Os estudos organizacionais têm suas raízes históricas em trabalhos que adquiriam relevância na segunda metade do século XIX. Dessa forma, esse século marca as origens dos estudos organizacionais, com os estudos de Simon, mais especificamente com o marco estabelecido por Chester Barnard. Ao publicar seu único livro em que aborda as funções do executivo em 1938, Barnard considera a organização como unidade de análise essencial. Até por volta dos anos de 1960, a análise organizacional era considerada simples e o modelo racional era hegemônico e, portanto, pouco questionado (BURREL, 2007).

O contexto atual, caracterizado pela evolução tecnológica e pelo aumento da competitividade empresarial, implicou mudanças no mundo do trabalho. As transformações e o desenvolvimento de tecnologias, que a princípio deveriam liberar o indivíduo da sobrecarga de trabalho, parecem tê-lo colocado ainda sob mais pressão (GAULEJAC, 2006). Assim, segundo o autor, apesar de a tecnologia ter tornado mais leve o desgaste físico, ela acabou aumentando a pressão psicológica.

Essa nova organização do trabalho, fundamentada exclusivamente no aspecto econômico, promove uma quebra das relações de trabalho e uma legitimação da competição acirrada em todos os níveis. Promove ainda uma individualização das culpas e dos prejuízos pelo não cumprimento de metas descabidas. Essa guerra econômica acaba servindo de álibi para justificar a sobrevivência da empresa a qualquer custo, gerando um ambiente de trabalho em que a violência se instala (FREITAS; HELOANI; BARRETO, 2017).

$O$ trabalho e a violência moral são fenômenos antigos. No entanto, o tema da violência moral ganhou maior destaque como um fator capaz de desencadear sofrimento no trabalho especialmente devido à flexibilização das relações trabalhistas e às mudanças ocorridas no mundo do trabalho (EINARSEN et al., 2005).

$\mathrm{O}$ assédio moral é um tema que vem ganhando cada dia mais espaço na sociedade. Em uma linguagem simplificada pode se dizer que se caracteriza por condutas inadequadas e que trazem prejuízos para o indivíduo no seu local de trabalho. Segundo Nunes, Tolfo e Nunes (2013), na literatura sobre o tema encontram-se especialmente autores de áreas afins da administração e da psicologia, principalmente da psicologia organizacional e do trabalho. No entanto, de acordo com Rodrigues e Freitas (2014) o tema só passou a ganhar notoriedade a partir das publicações da psiquiatra e psicoterapeuta familiar francesa Marie France Hirigoyen e do alemão Heinz Leymann.

O assédio moral pode assumir formas diferentes nos setores privado e público. No setor privado tornase mais evidente, pois tem duração menor e culmina com a saída do indivíduo assediado. Já no setor público o assédio moral pode se estender por anos, uma vez que a princípio os servidores são protegidos e não podem ser demitidos a não ser que ocorra uma infração muito grave (HIRIGOYEN, 2017b). Ainda segundo a autora, no setor público, como está voltado para o bem público, o assédio parece chamar muito mais a atenção e percebe-se que geralmente a sua ocorrência não está relacionada à produtividade, mas às disputas de poder.

Assim, analisar o assédio moral como um problema das organizações pode propiciar um ambiente de trabalho mais colaborativo e mais saudável tanto para as pessoas como para os negócios. O ambiente empresarial necessita manter certo nível de credibilidade a fim de que possa despertar a fidelidade de seus consumidores e a dedicação de seus membros. Um ambiente empresarial mortífero é contrário aos seus interesses mais caros e, além disso, nenhuma empresa pode prescindir de legitimidade social (FREITAS; HELOANI; BARRETO, 2017).

Nesse contexto, a presente pesquisa pretende responder à seguinte questão: quais as políticas institucionais e estratégias implementadas no Instituto Federal Catarinense frente à problemática do assédio moral no espaço acadêmico e administrativo? Assim, esta pesquisa se propõe a contribuir para a promoção de uma melhor qualidade de vida dos profissionais, promovendo um ambiente de trabalho mais saudável que vai refletir na melhoria dos índices de produtividade e no sucesso das organizações.

Dessa forma, esta pesquisa tem por objetivo geral perscrutar as estratégias de gestão no Instituto Federal Catarinense para conscientização e prevenção dos liames do assédio moral no âmbito educacional e administrativo. Apresenta ainda os seguintes objetivos específicos: conhecer as normas e procedimentos referentes ao assédio moral na instituição; caracterizar os casos de assédio moral formalizados na instituição; 
descrever políticas, programas e ações para a prevenção do assédio moral na organização; e identificar a visão dos entrevistados sobre o assédio moral e as políticas institucionais para a sua prevenção.

É importante destacar que tais estudos também podem contribuir para que o assédio moral possa ser prevenido ou minimizado no interior das organizações, uma vez que tais abusos podem ocasionar danos à subjetividade, dignidade ou integridade física ou psíquica dos indivíduos, desestabilizando-os perante os colegas e a organização, e colocando em risco seu próprio emprego e sua ascensão e realização profissional (HIRIGOYEN, 2017a).

Por fim, as contribuições deste estudo podem se dar ainda pela oportunidade de reflexão e conscientização às vítimas de assédio moral, no sentido de perceberem a sua condição de assediadas, levandoas a buscar formas de romper as barreiras do silêncio e do medo que as paralisam e as impedem de se livrar dessa condição.

\section{ASSÉDIO MORAL NO TRABALHO}

Heinz Leymann é considerado o precursor dos estudos sobre o assédio moral no trabalho. Embora tenha nascido na Alemanha, Leymann tornou-se doutor em Psicologia do Trabalho e mudou-se para a Suécia, onde assumiu uma cadeira na Universidade de Estocolmo, em que se dedicou à pesquisa sobre ambiente de trabalho e saúde. No início dos anos de 1980 ele iniciou suas pesquisas sobre o sofrimento no trabalho, chegando a resultados interessantes que o levaram a ampliar a sua pesquisa em nível nacional, incluindo posteriormente outros países de língua alemã (FREITAS; HELOANI; BARRETO, 2017).

Ainda de acordo com Freitas, Heloani e Barreto (2017), as contribuições de Marie France Hirigoyen, psiquiatra, psicanalista e psicoterapeuta familiar, foram muito importantes, e se deram especialmente pela publicação em 1998, na França, do livro Le harcèlement moral: la violence perverse au quotidien, que se tornou rapidamente um best-seller. Nesse livro, a autora utilizou pela primeira vez a expressão "assédio moral" para falar da violência no ambiente familiar e no mundo do trabalho. A obra instigou um amplo debate nos mais diversos setores da sociedade, em jornais, revistas especializadas e na TV.

Com relação à emergência de estudos e pesquisas no Brasil sobre o assédio moral no trabalho, Freitas, Heloani e Barreto (2017) destacam as contribuições dos trabalhos e publicações de alguns autores, como Freitas (2005; 2006; 2007a; 2007b; 2007c), Heloani (2003; 2004; 2006) e Barreto (2000; 2005).

Embora o assédio moral seja um tema amplo, complexo e sem consenso na literatura, é importante conhecer algumas definições sobre assédio moral. Para Marie France Hirigoyen, que conforme citado anteriormente foi uma das pioneiras no tema, o assédio moral no trabalho é

[...] toda e qualquer conduta abusiva, manifestando-se sobretudo por comportamentos, palavras, atos, gestos, escritos que possam trazer dano à personalidade, à dignidade ou à integridade física ou psíquica de uma pessoa, pôr em perigo seu emprego ou degradar o ambiente de trabalho. (HIRIGOYEN, 2017a, p. 65).

Nesta pesquisa optou-se pela definição de assédio moral apresentada por Freitas, Heloani e Barreto (2017), uma vez que esta enfoca os aspectos referentes à frequência, persistência e repetição dos comportamentos abusivos que são consensuais na literatura acadêmica sobre assédio moral. Dessa forma, assédio moral é

Uma conduta abusiva e intencional, frequente e repetida, que ocorre no ambiente de trabalho e que visa a diminuir, a humilhar, a vexar, a constranger, a desqualificar e a demolir psiquicamente um indivíduo ou um grupo, degradando as suas condições de trabalho, atingindo a sua dignidade e colocando em risco a sua integridade pessoal e profissional. (FREITAS; HELOANI; BARRETO, 2017, p. 37).

Assim, o assédio moral pode não ser percebido em um primeiro momento em que as pessoas ofendidas preferem levar na brincadeira as situações de desavenças e maus-tratos. Porém, em um momento 
posterior os ataques vão se intensificando de forma que a vítima seja seguidamente inferiorizada e hostilizada por um período maior (HIRIGOYEN, 2017b).

Um dos fatores determinantes para a incidência de assédio nas organizações é a cultura e o clima organizacional. A cultura organizacional está relacionada às normas, crenças e valores vivenciados pelos membros de uma organização. $O$ assédio moral pode ser considerado parte da cultura, sendo aceito como uma forma de realizar tarefas que são impostas (SALIN, 2003).

Em organizações em que o assediador tem a certeza da impunidade devido à ausência de políticas de prevenção e punição, o assédio tende a se elevar continuamente. Assim, o assédio passa a ser uma tática para se obter um desempenho satisfatório e melhorar as condições dentro da empresa (NUNES, 2011).

Conforme afirma Hirigoyen (2017b), muitos estudos foram desenvolvidos por diferentes autores sobre as atitudes hostis que caracterizam o assédio moral. Segundo a autora, essas atitudes hostis são agrupadas em quatro categorias, começando pela mais difícil de destacar até a mais evidente. São elas: deterioração proposital das condições de trabalho, 0 isolamento e a recusa de comunicação, os atentados contra a dignidade e a violência verbal, física ou sexual.

Um dos elementos mais citados pelos autores para caracterizar o assédio moral são a frequência e o tempo de duração das ações consideradas hostis. São esses aspectos que diferenciam, por exemplo, o conflito do assédio (SALIN, 2003).

De acordo com Hirigoyen (2017b) o assédio moral pode se dar de quatro formas diferentes: o assédio vertical descendente (que vem da hierarquia), o assédio vertical (que vem dos colegas), o assédio misto e o assédio ascendente.

Visto que o assédio moral se constitui em um fenômeno amplo e complexo, suas consequências e impactos podem ser profundos na vida do trabalhador, trazendo consequências diversas. A extensão desses impactos não se limita ao âmbito da relação assediador-assediado, podendo assumir proporções maiores que afetam, além da empresa, toda a sociedade (RODRIGUES; FREITAS, 2014).

É importante a conscientização de todos de que o assédio moral é um fenômeno devastador não somente na vida de um indivíduo, mas também da empresa e da sociedade, portanto diz respeito a todos. Assim, profissionais e organizações não podem fechar os olhos diante dessa questão, caso contrário estarão reforçando um comportamento que fere o direito que as pessoas têm de serem tratadas e respeitadas enquanto seres humanos. Dessa forma, é preciso ter claro que o assédio moral vai além de uma questão moral. Constitui-se também em uma questão econômica, além de ser um crime que deve ser punido de forma exemplar (FREITAS; HELOANI; BARRETO, 2017).

O assédio moral apresenta características diferentes de um setor para o outro. No setor privado é mais perceptível, tem duração de tempo menor e quase sempre termina com a saída do assediado. Já no setor público o assédio moral pode se estender por muitos anos, uma vez que, em princípio, os servidores são protegidos, não podendo ser demitidos, salvo nos casos em que se comete alguma falta muito grave. Em virtude dessa situação, os casos de assédio moral no setor público são mais nocivos e por essa razão acabam trazendo sérias consequências para a saúde do servidor (HIRIGOYEN, 2017b).

Visto que esta pesquisa foi desenvolvida em uma instituição pública de ensino, é importante destacar a afirmação de Hirigoyen (2017b) de que uma das áreas mais afetadas pelo assédio moral é a da educação. Segundo a autora, na área da educação, mais especificamente no campo da pesquisa, o assédio moral é considerado um fenômeno de sobrevivência, pois poucos conseguem alcançar algum reconhecimento ou status. Muitos ficam acumulando rancor e inveja e aproveitando-se dos colegas com maior notoriedade (HIRIGOYEN, 2017b).

Com relação aos aspectos legais sobre o assédio moral no serviço público, Marazzo et al. (2017, p. 48) afirma: "No ordenamento jurídico brasileiro o assédio moral ainda não foi tipificado como crime, embora existam várias leis municipais e estaduais que protegem o servidor público em alguns Estados, o que significa que o trabalhador não está desamparado".

No âmbito do serviço público, também não existe uma legislação específica sobre o assédio moral no trabalho. No entanto, segundo informações do Conselho Nacional do Ministério Público (CNMP) (2016), a Lei 8.112/90 traz alguns elementos importantes para o tratamento do assédio moral no serviço público. Assim, é 
importante destacar que a prática do assédio moral afronta as proibições expressas na referida lei e, nesse caso, o acusado de assédio pode sofrer penalidades conforme a gravidade da situação.

Não se deve esperar por um número significativo de vítimas do assédio moral no trabalho para que haja uma reação. É importante agir antes de qualquer indício, pois casos semelhantes muito provavelmente estão ocorrendo de forma velada ou podem vir a ocorrer. Mais do que buscar a solução pontual de um problema, é preciso haver a compreensão de que se trata de uma questão de prevenção e gestão (HIRIGOYEN, 2017b).

Reafirmando a responsabilidade da organização e, especialmente das chefias, no combate ao assédio moral, Freitas, Heloani e Barreto (2017, p. 108-109) também concordam que para "erradicar a cultura da impunidade, da falta de respeito, da promiscuidade e da indigência moral no ambiente de trabalho é tarefa coletiva, que precisa da cooperação dos ocupantes de cargos mais elevados". Também para Nunes e Tolfo (2012) é de responsabilidade da organização, especialmente dos gestores, adotar medidas de prevenção e combate à violência no trabalho. No entanto, é necessário mais do que vontade e discursos vazios.

Com base em alguns autores, são descritas no Quadro 1 algumas sugestões de ações para a prevenção e o combate do assédio moral nas organizações.

Quadro 1 - Ações para a prevenção e o combate do assédio moral nas organizações

\begin{tabular}{|c|c|}
\hline Autor(a) & Sugestões de ações de prevenção \\
\hline $\begin{array}{c}\text { Hirigoyen } \\
(2017 a, 2017 b)\end{array}$ & $\begin{array}{l}\text { - Não ignorar o problema e reagir o mais cedo possível. } \\
\text { - Rever atitudes e métodos de gestão. } \\
\text { - Dar aos empregados boas condições de trabalho. } \\
\text { - Chefiar os subordinados com respeito. } \\
\text { - Reforçar o diálogo e a escuta nas relações profissionais. } \\
\text { - Educação dos responsáveis para levar em conta a pessoa humana e não } \\
\text { apenas a produtividade. } \\
\text { - Formar os dirigentes sindicais para que possam intervir no processo. } \\
\text { - Inserir nos regimentos internos e convenções coletivas das organizações } \\
\text { cláusulas de proteção contra o assédio moral. } \\
\text { - Ações para informação das vítimas, dos trabalhadores e das organizações } \\
\text { sobre o assédio moral. }\end{array}$ \\
\hline Einarsen e Hoel (2008) & $\begin{array}{l}\text { - Criação de um clima social com uma atmosfera aberta e respeitosa, com } \\
\text { tolerância à diversidade, e na qual a existência de frustração e atrito é } \\
\text { aceita, mas também propriamente administrada. } \\
\text { - Garantia de que os estilos de liderança e práticas administrativas na } \\
\text { organização sejam aplicados a todos os funcionários de forma igual, } \\
\text { garantindo tratamento justo e com respeito, e que a sensibilidade para } \\
\text { necessidades pessoais e vulnerabilidades seja levada em conta. } \\
\text { - Garantia de que os gestores tenham treinamento e capacidade necessária } \\
\text { para administrar conflitos. } \\
\text { - Construção de uma organização com metas, regras e responsabilidades } \\
\text { claras e nítidas, e com uma forte ética de trabalho. } \\
\text { - Criação e manutenção de uma cultura organizacional em que o assédio } \\
\text { moral e os maus-tratos aos funcionários não sejam tolerados. }\end{array}$ \\
\hline
\end{tabular}

Fonte: Hirigoyen (2017a, 2017b) e Einarsen e Hoel (2008) adaptado pelos autores (2019).

Por fim, é importante destacar que quaisquer medidas para prevenir e combater o assédio moral não serão fáceis de serem implementadas e executadas nas organizações. É sempre muito difícil trilhar um caminho diferente quando a impunidade e o descaso já estão consolidados na organização. No entanto é preciso acreditar que, ao zelar pelos seus interesses, a organização pode reconstruir uma mentalidade em que se compreenda que todos perdem com o assédio moral (FREITAS; HELOANI; BARRETO, 2017). 


\section{METODOLOGIA}

A pesquisa desenvolvida é de natureza qualitativa orientada pelo paradigma interpretativo. A abordagem qualitativa, segundo Minayo (2008), não está restrita à quantificação, mas visa especialmente à compreensão dos caminhos que conduzem para as relações sociais em sua essência. Já com relação ao paradigma interpretativo, Vergara e Caldas (2007) afirmam que os interpretacionistas consideram as organizações como processos, teias de significados, de representações, de interações, de visões compartilhadas dos aspectos objetivos e subjetivos que fazem parte da realidade de pessoas, de movimentos, de ações de pessoas individual, grupal e socialmente consideradas.

Quanto aos seus objetivos, esta pesquisa se caracteriza por fazer parte do grupo das pesquisas exploratórias que, de acordo com Gil (2008), têm como principal finalidade desenvolver, esclarecer e modificar conceitos e ideias, visando à formulação de problemas mais precisos ou hipóteses pesquisáveis para estudos futuros.

Com relação às estratégias de investigação optou-se pela pesquisa bibliográfica, documental e estudo de caso. De acordo com Moreira (2002), a pesquisa bibliográfica consiste no exame da literatura científica para levantamento e análise do que já foi produzido sobre determinado tema. A pesquisa documental segundo Gil (2008) é muito semelhante à pesquisa bibliográfica, pois a única diferença entre ambas está na natureza das fontes, uma vez que essa utiliza materiais que não receberam ainda um tratamento analítico. Já, o estudo de caso, segundo Prodanov e Freitas (2013), consiste em coletar e analisar informações sobre determinado indivíduo, família, grupo ou comunidade, visando estudar aspectos variados de sua vida, de acordo com o tema da pesquisa.

A pesquisa foi desenvolvida no Instituto Federal Catarinense, que conta atualmente com quinze campi e possui a sede da reitoria em Blumenau.

Para responder às questões centrais desta pesquisa e atingir os objetivos propostos, em um primeiro momento foi desenvolvida uma revisão bibliográfica que buscou aprofundar os conhecimentos sobre o assédio moral no trabalho. Em um segundo momento, realizou-se uma pesquisa documental junto ao Instituto Federal Catarinense, onde foi possível identificar os órgãos responsáveis pela gestão do assédio moral na instituição e alguns dados sobre os casos de assédio moral formalizados na instituição. Em um terceiro momento foram realizadas entrevistas com oito servidores da Reitoria e do campus Santa Rosa do Sul para identificar o conhecimento deles sobre o tema e colher sugestões de estratégias para combater e prevenir o assédio moral no trabalho.

A pesquisa documental foi realizada no intervalo de tempo de 2014 a 2018 por meio do acesso às informações e documentos publicados nas páginas da Instituição, incluindo as páginas da Corregedoria, da Comissão de Ética e da Ouvidoria. A pesquisa documental permitiu conhecer os aspectos legais, os procedimentos e normas, as estratégias, além de fazer um levantamento de dados sobre os casos de assédio moral formalizados na instituição.

Após a conclusão da pesquisa documental foram realizadas entrevistas presenciais no ano de 2019 com oito servidores da instituição, sendo dois do Campus Santa Rosa do Sul e seis da Reitoria. Como critério para escolha dos entrevistados optou-se por aqueles cujas funções e atribuições têm relação direta com a questão do assédio moral, como a Corregedoria, a Comissão de Ética e a Ouvidoria, ou pelo fato de exercerem cargos ou funções estratégicas no âmbito da gestão da instituição, sendo, portanto, responsáveis por todos os aspectos da sua gestão, o que inclui a questão do assédio moral no trabalho.

A análise de conteúdo das informações obtidos na realização das entrevistas foi realizada de acordo com as três fases propostas por Bardin (2006): a pré-análise, a exploração do material e o tratamento dos resultados. $O$ tratamento dos resultados possibilitou a elaboração das categorias de análise a partir das palavras-chave ou ideias-chave identificadas nas falas dos entrevistados.

Os resultados obtidos foram apresentados na forma de gráficos e quadros, e por meio da transcrição direta das falas dos entrevistados, quando estas foram consideradas relevantes para evidenciar a relação com os objetivos propostos pela pesquisa e discutidos à luz de alguns autores citados na fundamentação teórica. 


\section{APRESENTAÇÃO E DISCUSSÃO DOS RESULTADOS}

Nesta seção serão apresentadas considerações sobre a realização da pesquisa documental e seus resultados, abordando os órgãos estratégicos para a gestão do assédio moral no IFC e os casos de assédio moral formalizados na instituição. Na sequência, apresenta e discute os resultados das entrevistas realizadas com alguns servidores da instituição.

\subsection{Pesquisa documental}

A pesquisa documental foi realizada por meio do acesso aos documentos e relatórios publicados na página da instituição. Cabe destacar que o pesquisador solicitou o acesso aos documentos internos da Corregedoria visando obter dados mais detalhados sobre os casos de assédio moral formalizados na instituição, porém o acesso foi negado alegando-se sigilo da documentação.

A pesquisa documental foi realizada no intervalo de tempo de 2014 a 2018, ou seja, observando-se o período dos últimos cinco anos.

\subsection{1 Órgãos estratégicos para a gestão do assédio moral no IFC}

A instituição conta atualmente com três órgãos estratégicos para a gestão do assédio moral na instituição: Corregedoria, Comissão de Ética e Ouvidoria. Cabe destacar, no entanto, que até o ano de 2016 existia a Coordenação-Geral de Procedimentos Administrativos Disciplinares (COOPAD), que foi substituída pela Corregedoria.

Considerando a centralidade e a importância desses órgãos no desenvolvimento de estratégias e políticas de gestão do assédio moral na instituição, bem como da COOPAD, que atuou até 2016, serão apresentadas a seguir algumas informações breves sobre esses órgãos.

a) Coordenação-Geral de Procedimentos Administrativos Disciplinares (COOPAD)

A COOPAD foi um órgão suplementar de assessoramento, acompanhamento e execução de procedimentos administrativos disciplinares oriundos dos campi e das unidades administrativas. Além disso, realizava sindicâncias no âmbito da Reitoria. A Resolução CONSUPER no 055, de 15 de dezembro de 2016, criou a Corregedoria, em substituição à estrutura da COOPAD.

b) Corregedoria

A Corregedoria do IFC é um órgão de correição, ou seja, que trata das questões disciplinares. No IFC, a Corregedoria está ligada ao gabinete do(a) reitor(a) e pertence à estrutura denominada "Sistema de Correição do Poder Executivo Federal", integrada pela Corregedoria-Geral da União como "órgão central", pelas unidades específicas de correição junto aos ministérios como "unidades setoriais" e pelas unidades específicas de correição que compõem as estruturas dos ministérios, das autarquias e das fundações públicas como "unidades seccionais" - Decreto 5.480 de 30/06/2005 (BRASIL, 2005).

Segundo o artigo $4^{\circ}$ da Resolução CONSUPER n 055/2016, a Corregedoria será encarregada das atividades relacionadas à prevenção, detecção e apuração de possíveis irregularidades disciplinares e administrativas de servidores públicos e pessoas jurídicas no âmbito do Instituto Federal de Educação, Ciência e Tecnologia Catarinense (IFC), devendo exercê-las com base na lei, com autonomia e independência, observando a atuação dos servidores integrantes de seu quadro por padrões éticos de imparcialidade, isenção, integridade moral e honestidade.

Para a realização das atividades correcionais, a Corregedoria utiliza de comissões compostas de servidores (internos e externos) e se desenvolve por meio dos seguintes instrumentos: Processo Administrativo Disciplinar (PAD), Sindicância (punitiva e investigativa), Sindicância Patrimonial e Investigações Preliminares (IFC, 2019). 


\section{c) Comissão de Ética}

Em consonância com a legislação que trata do tema, foi criada a Comissão de Ética do Instituto Federal Catarinense, que tem como objetivo promover a gestão da ética por meio de orientações, recomendações e esclarecimentos sobre as mais variadas questões ligadas à conduta profissional de seus servidores.

O IFC adota o Código de Ética Profissional do Servidor Público Civil do Poder Executivo Federal. A Comissão de Ética do IFC tem missão primordialmente pedagógica e não punitiva, objetivando atuar de forma preventiva com relação a possíveis desvios de conduta dos servidores da instituição. Contudo, na ocorrência de desvios ou transgressões das normas de conduta, a Comissão de Ética pode propor a adoção de procedimentos corretivos que se façam necessários.

d) Ouvidoria

A Ouvidoria é um canal de comunicação entre a administração do Instituto Federal Catarinense e a comunidade interna e externa, que tem por finalidade dar os devidos encaminhamentos referentes aos serviços prestados pela instituição.

A Ouvidoria não tem poder decisório, mas tem ampla autonomia no acesso a todas as instâncias do IFC. Não litiga; antes, busca a harmonização, agindo como conciliadora.

\subsubsection{Os casos de assédio moral formalizados no IFC}

Os casos de assédio moral formalizados no IFC entre 2014 e 2018 aqui apresentados foram transcritos dos Relatórios de Gestão e Relatórios de atividades de correição da Corregedoria. No entanto, é importante destacar que os respectivos relatórios trazem o registro de denúncias e representações que versam sobre diversos temas, sendo que o pesquisador realizou uma triagem dos casos que envolviam apenas a questão do assédio moral.

O Gráfico 1, apresentado a seguir, permite facilitar a visualização do quantitativo anual de processos administrativos disciplinares/sindicâncias sobre assédio moral formalizados na Corregedoria do IFC no período de 2014 a 2018.

Gráfico 1 - Número de processos administrativos disciplinares/sindicâncias sobre assédio moral formalizados no IFC no período de 2014 a 2018

\section{Quantidade de processos admistrativos disciplinares/sindicâncias formalizados de 2014 a 2018.}

9

8

7

6

6

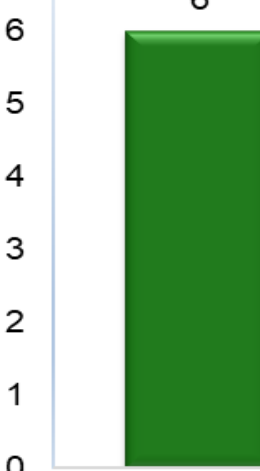

0

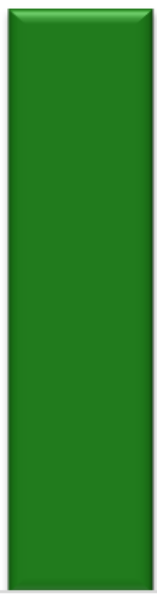

6 2014 2015 2016

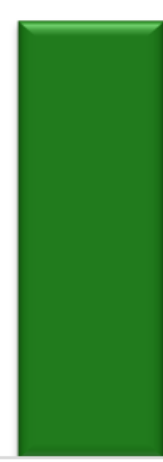

2017
6

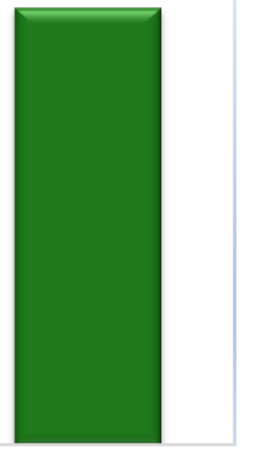

2018

Fonte: Relatórios de Gestão e de Atividades de Correição de 2014 a 2018. Adaptado pelos autores (2019). 
O gráfico acima demonstra que no ano de 2016 ocorreu o maior número de processos administrativos disciplinares/sindicâncias de casos de assédio moral formalizados na instituição, com um total de 8 processos. Já nos anos de 2014, 2017 e 2018 observa-se que o número de processos se manteve constante, com um total de 6 processos em cada ano.

O ano de 2015 aparece com nenhum caso porque o Relatório de Gestão do IFC 2015 não apresentou os dados detalhados das denúncias e representações formalizadas, não sendo possível a identificação dos casos relacionados a assédio moral.

\subsection{Apresentação e discussão dos resultados das entrevistas}

Foram entrevistados ao todo oito servidores(as), sendo dois no campus Santa Rosa do Sul e seis na Reitoria, cujas funções e atribuições têm relação direta com a questão do assédio moral no trabalho, por se tratar de cargos ou funções estratégicas no âmbito da gestão da instituição.

Cabe ressaltar ainda que na apresentação e discussão dos resultados algumas informações, bem como os nomes do(as) entrevistados(as), foram omitidas para garantir o anonimato dos respondentes. Dessa forma, os entrevistados serão identificados pela letra $E$ seguida dos números de 1 a 8.

O roteiro elaborado previamente para as entrevistas contou com um total de seis questões, que tiveram por objetivo obter informações que permitissem traçar os perfis dos entrevistados, bem como responder às questões e aos objetivos propostos nesta pesquisa.

\subsubsection{O perfil dos entrevistados}

Antes do início das entrevistas, os pesquisadores preencheram um breve formulário onde foram coletadas algumas informações sobre dados pessoais e profissionais dos entrevistados que permitiram traçar os seus perfis. Além disso, as respostas obtidas na primeira questão da entrevista, onde os entrevistados fizeram uma breve apresentação pessoal e profissional, também possibilitaram complementar as informações que permitiram traçar esse perfil.

O Quadro 2 a seguir apresenta alguns aspectos referentes ao perfil dos entrevistados.

Quadro 2 - Perfil dos servidores entrevistados

\begin{tabular}{|c|c|c|c|c|c|c|c|}
\hline $\begin{array}{c}\text { Entrevistado } \\
\text { NNo }\end{array}$ & Sexo & Idade & $\begin{array}{c}\text { Última } \\
\text { formação }\end{array}$ & Lotação & $\begin{array}{c}\text { Tipo de } \\
\text { vínculo }\end{array}$ & $\begin{array}{c}\text { Cargo } \\
\text { Dir./Coord./Chef. }\end{array}$ & $\begin{array}{c}\text { Data da } \\
\text { entrevista }\end{array}$ \\
\hline E1 & M & 41 & Mestrado & $\begin{array}{c}\text { Campus } \\
\text { SRS }\end{array}$ & Docente & Sim & $11 / 11 / 2019$ \\
\hline E2 & M & 38 & Mestrado & $\begin{array}{c}\text { Campus } \\
\text { SRS }\end{array}$ & TAE & Sim & $11 / 11 / 2019$ \\
\hline E3 & M & 30 & Especialização & Reitoria & TAE & Sim & $27 / 11 / 2019$ \\
\hline E4 & M & 58 & Especialização & Reitoria & TAE & Não & $27 / 11 / 2019$ \\
\hline E5 & F & 34 & Especialização & Reitoria & TAE & Sim & $04 / 12 / 2019$ \\
\hline E6 & F & 58 & Especialização & Reitoria & TAE & Sim & $04 / 12 / 2019$ \\
\hline E7 & F & 46 & Especialização & Reitoria & TAE & Sim & $04 / 12 / 2019$ \\
\hline E8 & F & 51 & Doutorado & $\begin{array}{c}\text { Campus } \\
\text { Camboriú }\end{array}$ & Docente & Sim & $04 / 12 / 2019$ \\
\hline
\end{tabular}

Fonte: elaborado pelos autores (2019).

Pelos dados apresentados no Quadro 2, observa-se que houve equidade com relação ao sexo dos entrevistados e que a maioria (cinco entrevistados) está situada em uma faixa etária superior a quarenta anos. Observa-se ainda que a ampla maioria (seis) dos entrevistados são técnico-administrativos com até dez anos de trabalho na instituição.

Alguns entrevistados evidenciaram as experiências que tiveram a oportunidade de vivenciar ou que ainda estão vivenciando na instituição na área de gestão, conforme pode ser observado nas falas dos entrevistados destacadas abaixo: 
E1: “ocupei cargo de gestão no ano de 2012 a 2016 como coordenador geral de ensino [...] também trabalhei com comissões, grupos de trabalho na instituição, sempre fui demandado, sempre tive participação, enfim, essa é um pouco da minha trajetória aqui dentro da instituição".

E7: "Trabalhei com os três gestores que por aqui passaram, e paralelo a trabalhar no gabinete eu já desde 2014 fazia processo administrativo disciplinar, faço até hoje ainda, e fui presidente de comissão de ética. [...] e nesse sentido paralelo também continuei fazendo os processos administrativos [...]".

A experiência em gestão, abordada por quatro entrevistados, foi importante, na medida em que lhes permitiu contribuir, de forma mais efetiva, considerando as possíveis situações de assédio moral vivenciadas ao longo de suas trajetórias profissionais.

\subsubsection{Definição dos entrevistados sobre o assédio moral no trabalho}

Na segunda questão da entrevista os entrevistados foram questionados sobre o que entendem por assédio moral no trabalho, e as respostas podem ser observadas no Gráfico 2 a seguir.

Gráfico 2 - Definição de assédio moral no trabalho

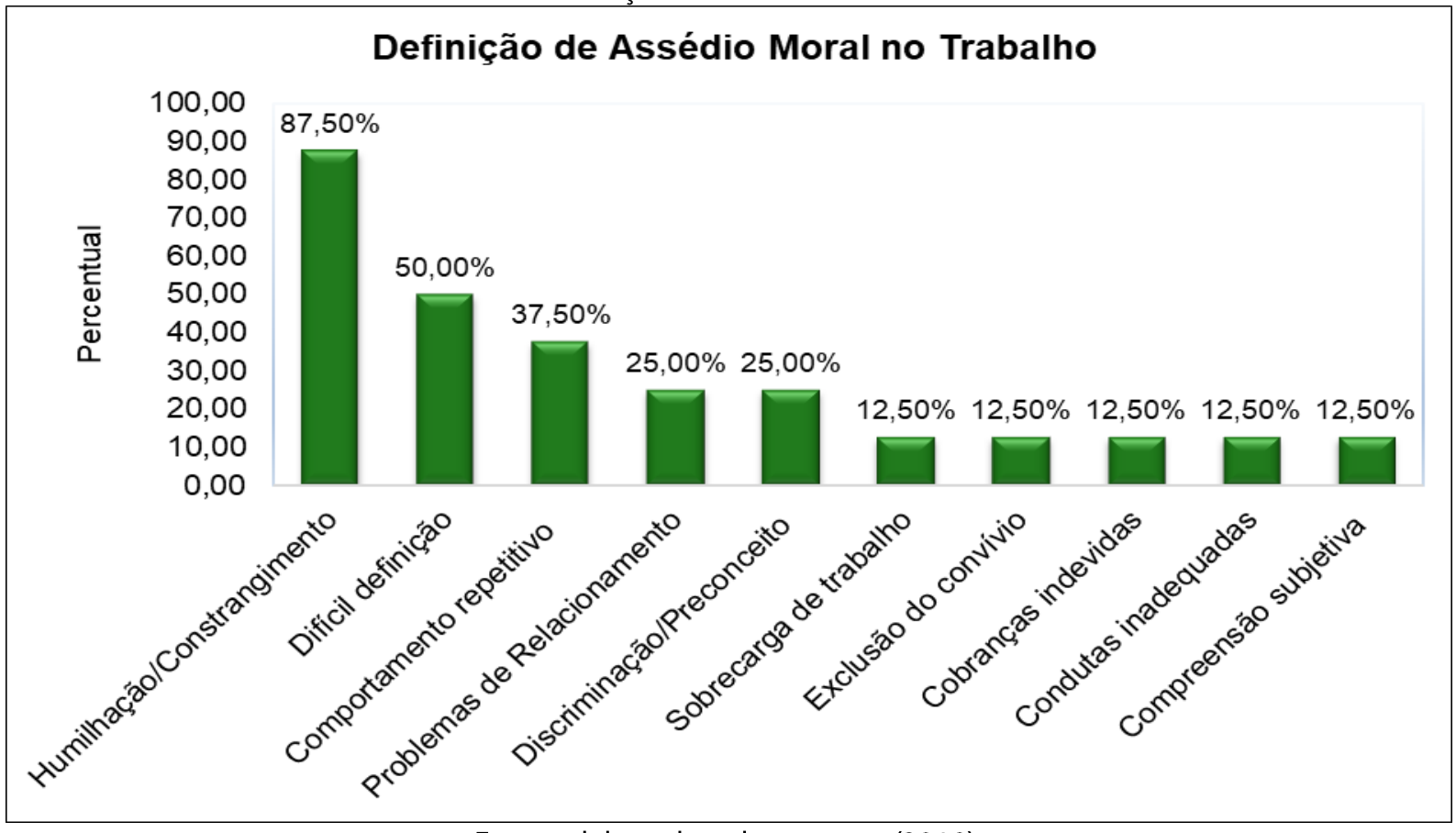

Fonte: elaborado pelos autores (2019).

Observando-se as respostas no gráfico acima, percebe-se que a ampla maioria dos entrevistados, com um percentual de $87,5 \%$ (sete entrevistados), entende o assédio moral no trabalho como uma humilhação e/ou constrangimento causado a um colega de trabalho. Tais afirmações podem ser observadas claramente nas falas de dois entrevistados:

E4: “[...] por vezes o assediador não se dá conta e a vítima não se dá conta também. Quando ocorre é humilhante e degradante [...]".

E6: "O assédio moral no trabalho é uma situação em que determinado servidor passa por humilhação, constrangimento, algo que o incomode no dia a dia [...]".

Cabe destacar que essa definição dos entrevistados está de acordo com a definição de assédio moral adotada nesta pesquisa apresentada por Freitas, Heloani e Barreto (2017). Segundo essa definição, o assédio moral é uma conduta abusiva que ocorre no ambiente de trabalho e que visa a diminuir, humilhar e constranger um indivíduo ou um grupo.

Metade dos entrevistados, ou seja, 50\% (quatro entrevistados), consideram que é difícil definir o que é assédio moral no trabalho, conforme pode ser observado na fala deste entrevistado: 
E3: "Eu acho que é muito difícil hoje a gente caracterizar o que é assédio moral e o que é uma conversa, ou alguma coisa nesse sentido [...]".

Essa dificuldade na definição ou na compreensão do assédio moral também é observada nos trabalhos de Corrêa e Carrieri (2004), para quem esse fenômeno é pouco compreendido pelo grande público.

\subsubsection{Visão dos entrevistados sobre o tratamento dos casos de assédio moral na instituição}

Na terceira questão da entrevista, os entrevistados responderam se consideram adequada a forma como os casos de assédio moral são tratados na instituição, e a resposta pode ser observada no Gráfico 3, a seguir.

Gráfico 3 - Você considera que os casos de assédio moral são tratados/encaminhados de forma adequada na instituição?

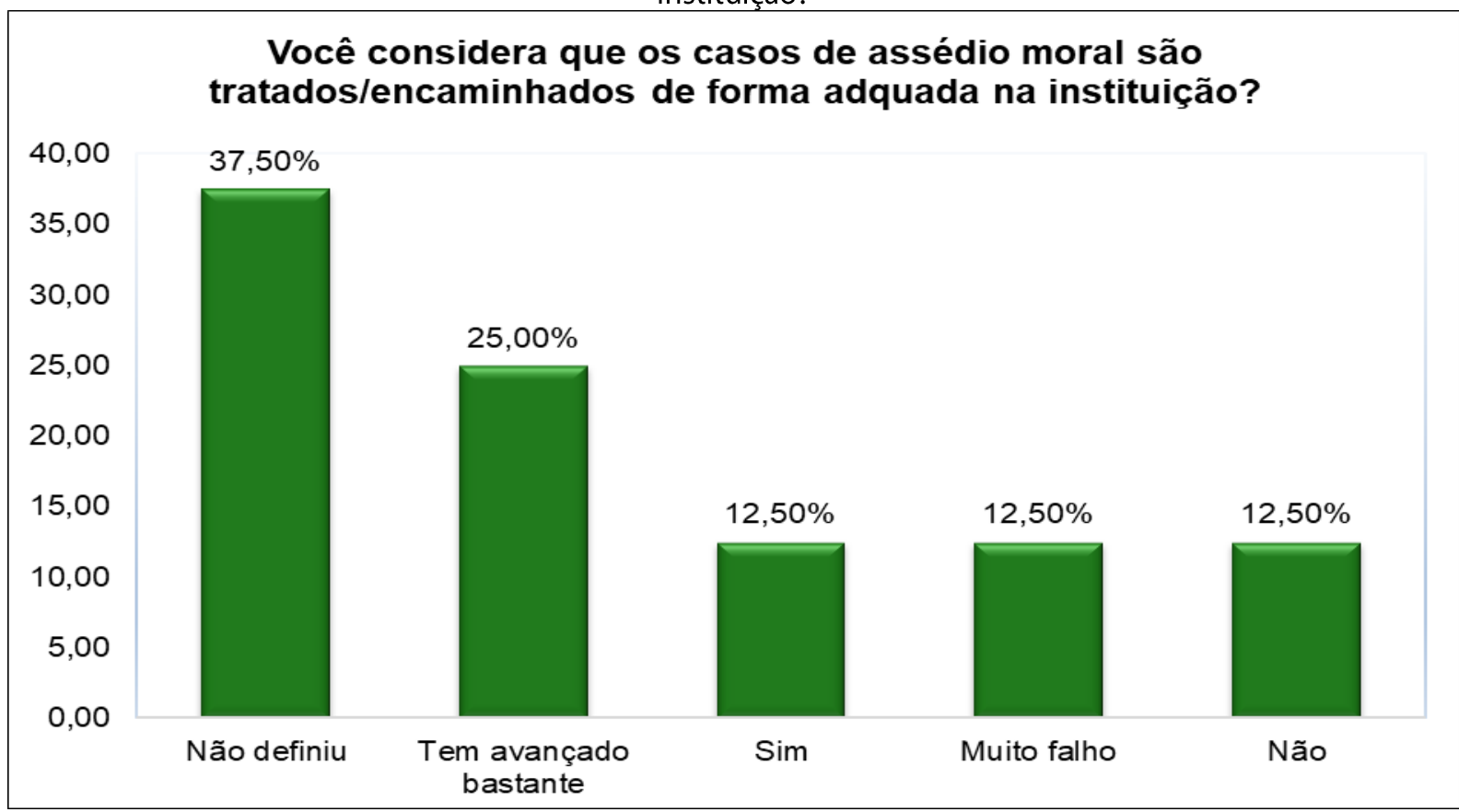

Fonte: elaborado pelos autores (2019).

Observando-se os dados apresentados no Gráfico 3 percebe-se que a resposta "não definiu" obteve o maior percentual, de 37,5\% (três entrevistados), entre os entrevistados. Nesse caso, os entrevistados preferiram fazer considerações sobre a forma como os casos de assédio moral são encaminhados na instituição e/ou citar exemplos sem, no entanto, explicitar sua opinião se consideram adequado ou não a forma como a instituição trata esses casos. Algumas dessas considerações podem ser observadas nos relatos abaixo.

E1: "A questão do assédio moral primeiramente tem toda uma questão que depende das pessoas, primeiramente às vezes as pessoas até são assediadas moralmente, mas elas mesmas não querem acionar seus direitos no âmbito institucional, procurar se defender, porque há todo um desgaste por trás da situação [...]".

E2: "É difícil dizer isso. [...] Por isso falo que é complicado, porque como a gente trabalha numa instituição que tem vários setores, [...] assédio moral não precisa ser teu chefe, pode ser teu colega, no nosso caso como trabalhamos com alunos, pode ser também algum aluno, então é difícil [...]".

Em segundo lugar, com 25\% (dois entrevistados), aparece a resposta "tem avançado bastante", revelando uma visão otimista dos entrevistados quanto à forma como a instituição vem tratando os casos de assédio moral, conforme pode-se observar nos relatos abaixo.

E3: "[...] eu acho que a gente tem avançado bastante nos modelos de ouvir e de investigar essas questões, e de fato saber se foi alguma coisa pontual ou se foi uma perseguição a ponto de ser considerado como assédio moral". 
E8: “Então eu vejo isso como, assim, formas ou práticas de gestão que ajudaram e vêm ajudando a gente a ter uma atitude mais adequada diante disso".

Observa-se que o relato do entrevistado 3 (E3) vem ao encontro às ações para a prevenção e o combate do assédio moral nas organizações, propostas por Hirigoyen (2017a, 2017b), ao citar que não se deve ignorar o problema e reagir o mais cedo possível, bem como, reforçar o diálogo e a escuta nas relações profissionais.

4.2.4 Nível de conhecimento das políticas, programas ou ações para a prevenção do assédio moral na instituição e avaliação da adequação/eficácia dessas estratégias

A quarta questão da entrevista objetivou saber se os entrevistados têm conhecimento das políticas, programas ou ações para a prevenção do assédio moral na instituição e, em caso positivo, como estes avaliam a adequação/eficácia dessas estratégias ou medidas.

A maioria dos entrevistados respondeu à questão tecendo diversas considerações, citando exemplos e, em alguns casos, avaliando essas políticas e estratégias adotadas pela instituição, o que dificultou a categorização das respostas e a organização na forma de gráfico. Algumas respostas com os relatos dos entrevistados são apresentadas a seguir.

\begin{abstract}
[...] quando chega ao nosso conhecimento qualquer denúncia relativa ao trabalho do servidor a gente encaminha toda a documentação recebida para a corregedoria, a corregedoria é que vai fazer o filtro dizendo se aquilo é um processo disciplinar ou se aquilo vai para uma comissão de ética, daí se vai para a comissão de ética quem faz o trabalho é a comissão de ética, se é um aspecto disciplinar quem faz o trabalho é uma comissão designada pela reitora, pela comissão processante e óbvio, tem os procedimentos legais, as formas, abrem-se os processos e aí existe a oportunidade da pessoa que está sendo prejudicada falar e também a pessoa que está sendo acusada ou investigada também de ouvir e se defender [...]". [...] em geral às vezes uma conversa, um entendimento entre as partes traz bons resultados, porque pode acontecer de ser uma questão bem pontual [...] não sei se é a melhor forma, mas tem solucionado as coisas de forma mais pacífica e de não causar outros transtornos em termos de relacionamento entre servidores. (E1).
\end{abstract}

Observa-se pelos relatos do entrevistado E1 que ele possui amplo conhecimento sobre as políticas e as estratégias de gestão da instituição frente ao assédio moral no trabalho.

Ao apontar a conversa e o diálogo como estratégias utilizadas para prevenir ou tratar a questão dos conflitos entre os servidores, evitando dessa forma que se consolide ou se confirme o assédio moral, o entrevistado demonstra sintonia com o pensamento de Hirigoyen (2017a), que também comenta sobre a importância do diálogo como estratégia de prevenção ao assédio moral no trabalho.

[...] como a gente não tem isso normatizado sobre como funciona, como acontece ou quem procurar eu acho que o certo seria você procurar primeiro a tua chefia, se não for ela a causadora do assédio, se for essa pessoa você procura o superior acima da função [...]". [...] agora tu também podes fazer uma denúncia para a ouvidoria ou para corregedoria. [...] Pode ser anônimo ou não, pode também mandar um e-mail, cria um e-mail alternativo, pode ser também com teu e-mail mesmo, explicando o que vem acontecendo, falando que tem testemunha, enfim [...] (E2).

Em um primeiro momento, percebe-se que o entrevistado E2 afirma que não há normatização na instituição, ou que o servidor não sabe a quem recorrer no caso de sofrer assédio moral. Porém, em um segundo momento ele aponta as formas e instâncias a que o servidor pode recorrer ou procurar auxílio ao sofrer assédio moral.

Os instrumentos legais ou as instâncias existentes na instituição são fundamentais para a prevenção e a minimização dos casos do assédio moral, pois conforme o entendimento de Einarsen e Hoel (2008), para prevenir o assédio moral, deve-se primeiramente garantir que os assediados tenham a quem ou onde encaminhar suas denúncias.

[...] a própria corregedoria que está fazendo um belo trabalho de orientação inicialmente, e depois de investigação através das comissões junto a todos os Campus do IFC". [...] tem avançado bastante, bastante coisa a gente tem respondido, tem orientado os campi [...]". E assim a própria legislação ainda 
é um pouco... não confusa, mas omissa em alguns casos que não nos deixam claro o que pode ser considerado, no meu ponto de vista, o que é considerado assédio moral. (E3).

Nos relatos percebe-se ainda que o entrevistado E3 enfatiza a importância da orientação aos servidores e, especialmente, aos gestores, citando algumas ações de capacitação desenvolvidas sobre o tema. A importância de trabalhar a prevenção também é compartilhada por Hirigoyen (2017b) ao afirmar que, mais do que buscar a solução pontual de um problema, é necessária a compreensão de que se trata de uma questão de prevenção e gestão.

A observação feita pelo entrevistado E3 sobre a falta de clareza e da suposta omissão da legislação também é destacada por Soares e Duarte (2014), que consideram insipiente a legislação brasileira sobre o assédio moral. Para os autores, ela apresenta fragilidades, especialmente quanto à definição e critérios que levem à configuração do assédio moral.

E4: "A Comissão de Ética faz um trabalho preventivo e minimizou várias demandas dentro do IFC. [...] Em 2016 ou 2017, a Comissão de Ética ficou classificada no Prêmio de Gestão Nacional de Gestão em boas práticas em ética". [...].

O entrevistado E4 fez um breve relato em que abordou especificamente o papel e a importância da Comissão de Ética da instituição. Ao comentar algumas ações desenvolvidas pela Comissão de Ética, o entrevistado faz uma avaliação positiva do seu trabalho, especialmente no que diz respeito à prevenção do assédio moral na instituição e à promoção de boas práticas.

Nesse contexto, Nunes e Tolfo (2012) também afirmam que para a prevenção do assédio moral no trabalho é necessário mais do que vontade e discursos vazios; é preciso sobretudo coragem para admitir a sua ocorrência e perseverança na construção de medidas éticas e boas práticas no ambiente de trabalho.

E5: "[...] eu acho que o assunto ainda dentro do Instituto, talvez ele fique muito perdido, sem pai nem mãe, quem é que trata? [...] mas, assim, a minha opinião enquanto servidora, eu acho que a forma de abordagem ainda é muito assim textos gigantes para leitura, o servidor não para pra ler, entendeu?".

Pelo relato apresentado acima, observa-se que a entrevistada $\mathrm{E} 5$ tece algumas críticas, especialmente com relação à falta de informação para os servidores sobre o tema e à forma como essas informações chegam até os servidores da instituição.

A importância da informação, tanto às vítimas como aos trabalhadores e a toda a organização, também é destacada por Hirigoyen (2017a, 2017b) como sugestão de ação para a prevenção do assédio moral nas organizações.

A entrevistada 6 (E6) optou por não responder a essa questão alegando o pouco tempo em que está no cargo.

\begin{abstract}
[...] porque às vezes, como para nós é difícil reconhecer que nós somos leigos às vezes tem alguma coisa acontecendo e as pessoas não conseguem identificar, que aquilo de fato é um assédio moral porque é uma brincadeirinha, é um abuso, é uma palavra, é alguma outra coisa, mas quanto mais gente tiver sendo conscientizada, mais soubermos sobre o assunto, mais fácil será o combate. [...] eu vejo que hoje a instituição ela está muito preocupada em evitar que o assédio exista, através dos esclarecimentos, cartilhas, está se fazendo um movimento em relação ao assédio moral. (E7).
\end{abstract}

Em seu relato a entrevistada E7 comenta sobre as dificuldades dos gestores e até dos próprios servidores em identificar o que é e o que não é assédio moral. Além disso, destaca a importância do conhecimento sobre o tema para evitar dúvidas e equívocos. Hirigoyen (2017b) também concorda que, para uma prevenção verdadeiramente eficaz, é importante e necessário distinguir o assédio moral de outras situações que podem ocorrer no ambiente de trabalho, como estresse, pressão, conflito velado, desentendimento e agressões pontuais.

[...] se você tem na cultura institucional esse ethos mais arrogante, e esse ethos no sentido de que eu tenho uma hierarquia e essa hierarquia me confere autoritarismo e não autoridade, e isso talvez seja, possa ser mais forte e quando isso é tratado de modo natural, que para mim não tem nada de natural, é um fato social, é um fato político [...] (E8). 
De acordo com a entrevistada E8, a cultura institucional pode favorecer ou inibir a ocorrência de assédio moral. Assim, por exemplo, uma cultura institucional fortemente hierarquizada, na qual autoridade é confundida com autoritarismo, o assédio moral pode ser naturalizado e não percebido como um fator social e político que permeia as relações de trabalho.

Sobre as relações entre cultura organizacional e assédio moral, Salin (2003) também entende que a cultura organizacional é um dos fatores determinantes para a incidência do assédio moral nas organizacionais. Segundo a autora, a cultura organizacional está relacionada às normas, crenças e valores vivenciados na organização. Dessa forma, o assédio moral pode ser considerado parte da cultura, sendo aceito como uma forma de realizar tarefas que são impostas.

\subsubsection{Sugestões dos entrevistados para aperfeiçoar as estratégias/políticas de gestão do assédio moral no IFC}

Na quinta questão da entrevista os entrevistados trouxeram sugestões para aperfeiçoar as estratégias/políticas de gestão do assédio moral no IFC. As respostas estão representadas no Gráfico 4.

\section{Gráfico 4 - Sugestões para aperfeiçoar as estratégias/políticas de gestão do assédio moral no IFC}

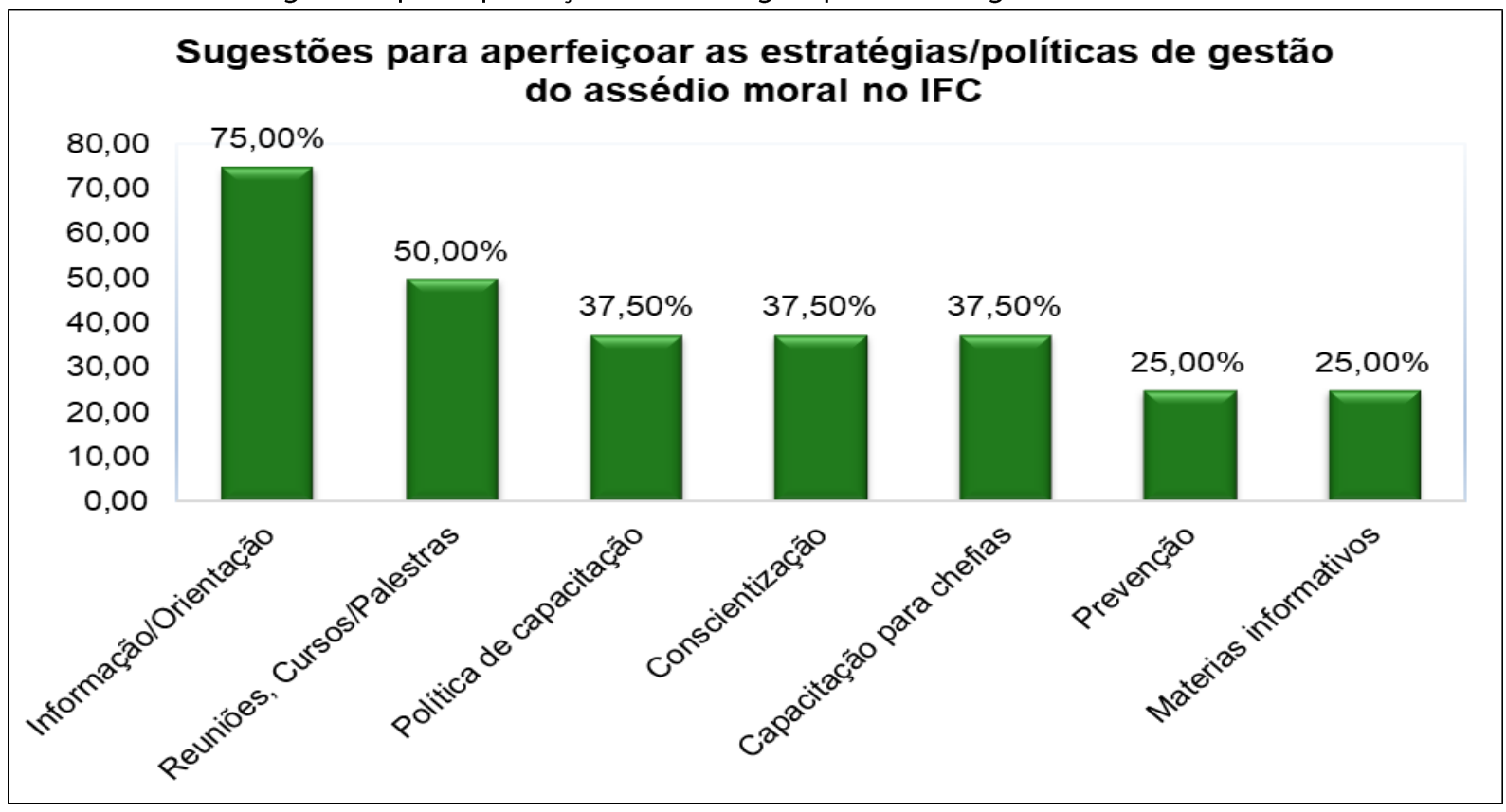

Fonte: elaborado pelos autores (2019).

Observando-se o gráfico 4, percebe-se que a resposta mais citada pelos entrevistados foi "Informação/Orientação" (seis entrevistados), que obteve um percentual de 75\%. A segunda resposta mais citada foi "Reuniões/Cursos/Palestras" (quatro entrevistados), com um percentual de 50\%. Em terceiro lugar, com um percentual de 37,5\% (três entrevistados), aparecem as respostas "Política de capacitação", "Conscientização" e "Capacitação para as chefias". Em quarto lugar, com um percentual de 25\% (dois entrevistados), aparecem as respostas "Prevenção", "Materiais informativos".

A necessidade de desenvolver ações que levem informação e orientação aos servidores da instituição pode ser observada nos relatos dos entrevistados E1 e E3 transcritos a seguir.

E1: “[...] então alguma informação, treinamento, falar o que é assédio, o que são processos... buscar a lei 8.112 o direito e os deveres dos servidores, isso é fundamental [...]". 
As sugestões que envolvem a realização de reuniões, cursos e palestras e para o desenvolvimento de uma política de capacitação e um processo de conscientização junto aos servidores da instituição, podem ser vistas nos relatos dos entrevistados E1 e E2 abaixo.

E1: "[...] o importante é fazer essas reuniões, esses cursos, essas palestras para que as pessoas saibam e se cuidem também, porque muitas vezes existem coisas que não são intencionais, as vezes a pessoa se descuida e entra numa situação que aquilo pode ser caracterizado como assédio [...]".

E2: "[...] a DGP, ela poderia fazer uma política de capacitação, não sei se capacitação seria a palavra correta com relação ao assédio, quando falo assédio é sexual e moral [...]".

Com relação à sugestão de elaborar materiais informativos sobre o tema é importante destacar o relato da entrevistada $\mathrm{E} 5$ que afirma:

E5: "Então eu acho que ainda faltam um pouco de pegar servidores no geral e fazer mais divulgação assim, de informação. E tem que ser simples, tem que ser material simples de bater o olho e entender o que está escrito ali. Não adianta mandar cartilha gigante, a gente sabe, o servidor não lê o e-mail que a gente manda entendeu?"

Percebe-se que todas as sugestões apresentadas pelos entrevistados visam à prevenção do assédio moral na instituição, que pode se dar por meio da orientação, do repasse de informações, da capacitação e do conhecimento sobre o tema.

A importância das ações de prevenção ao assédio moral no trabalho é enfatizada por Hirigoyen (2017b). Segundo a autora é necessário agir antes de qualquer indício, uma vez que casos de assédio moral podem estar ocorrendo de forma velada ou podem vir a ocorrer.

\subsubsection{Comentários dos entrevistados sobre assuntos e temas que não foram abordados na entrevista}

Na última questão da entrevista, os entrevistados foram convidados a comentar algum assunto ou tema que não tenha sido abordado na entrevista. Diante da natureza da questão, que permitiu ao entrevistado comentar qualquer assunto, as respostas foram bastante diversificadas, dificultando a categorização e a apresentação na forma de gráfico.

Assim, será apresentado no Quadro 3 uma síntese das ideias comentadas pelos entrevistados.

Quadro 3 - Comentários dos entrevistados sobre temas não abordados na entrevista

\begin{tabular}{|c|l|}
\hline Entrevistado(a) & \multicolumn{1}{c|}{ Comentários } \\
\hline E1 & $\begin{array}{l}\text {. Importância do trabalho desenvolvido pela Corregedoria. } \\
\text { Importância da visita do corregedor ao campus anualmente para palestras, em } \\
\text { virtude da grande rotatividade de servidores. }\end{array}$ \\
\hline E2 & $\begin{array}{l}\text {. Relato do trabalho e das atividades desenvolvidas no campus em relação ao } \\
\text { assédio moral. } \\
\text {. Necessidade de trabalhar o assédio moral num viés menos punitivo. }\end{array}$ \\
\hline E3 & $\begin{array}{l}\text { Importância de tratar o assédio moral, mas também das infrações ao Regime } \\
\text { Jurídico Único dos Servidores (Lei 8.112). }\end{array}$ \\
\hline E5 & $\begin{array}{l}\text {. Necessidade de mais orientações para os servidores para que saibam como } \\
\text { proceder quando precisarem de ajuda. } \\
\text {. Informação sobre o número de denúncias de assédio moral recebidas pela } \\
\text { ouvidoria ao longo do ano e sobre os encaminhamentos dados a essas denúncias. }\end{array}$ \\
\hline E8 & $\begin{array}{l}\text {. Importância de se preocupar não apenas com o assédio moral, mas com as } \\
\text { relações interpessoais e com o código de ética do servidor. } \\
\text {. Importância do servidor público e da educação pública e gratuita como um direito } \\
\text { de todos. }\end{array}$ \\
\hline
\end{tabular}

Fonte: elaborado pelos autores (2019).

Com exceção de dois entrevistados (E4 e E6) que não fizeram comentários, os demais entrevistados comentaram questões ligadas ao tema do assédio moral e ao dia a dia da instituição, citando algumas ideias e necessidades já sugeridas por eles na questão anterior. 
A importância das relações interpessoais no trabalho, citada pela entrevistada E8, que pressupõe uma atitude de escuta e de diálogo, é um aspecto também citado por Hirigoyen (2017a, 2017b) para a prevenção e o combate do assédio moral nas organizações. Da mesma forma, criar um clima de respeito às diferenças e de tolerância à diversidade, citada pela entrevistada, também é uma ação abordada por Einarsen e Hoel (2008) para a prevenção do assédio moral nas organizações.

\section{CONSIDERAÇõES FINAIS}

A presente pesquisa sobre o assédio moral no trabalho permitiu conhecer e aprofundar um tema relativamente recente, especialmente na literatura brasileira. No entanto, diante das limitações inerentes a qualquer estudo ou pesquisa, as considerações aqui apresentadas não têm a pretensão de dar conta da complexidade do tema, nem de apresentar todas as respostas às questões suscitadas ao longo da pesquisa. Antes, propõe-se a contribuir para as reflexões sobre a questão do assédio moral no trabalho, tema central desta pesquisa.

Os resultados da pesquisa documental permitiram concluir que atualmente existem três órgãos estratégicos para a gestão do assédio moral na instituição: Corregedoria, Comissão de Ética e Ouvidoria. Já, com relação aos casos de assédio moral formalizados no IFC entre 2014 e 2018 que foram transcritos dos Relatórios de Gestão e Relatórios de atividades de correição da Corregedoria, constatou-se que no ano de 2016 ocorreu o maior número de processos administrativos disciplinares/sindicâncias, com um total de 8 processos.

Com relação às entrevistas, observou-se que o conhecimento dos entrevistados sobre o que é assédio moral no trabalho muito provavelmente se deve ao fato de serem gestores ou ocuparem funções ou desempenharem atividades relacionadas a sua gestão na instituição. Esse aspecto pode ser considerado positivo, pois o conhecimento sobre o tema é condição fundamental para uma gestão adequada do assédio moral na instituição.

Quantos às ações e programas desenvolvidos na instituição para a prevenção do assédio moral no trabalho, os entrevistados citam algumas ações como cursos, palestra e visitas para orientações desenvolvidas nos campi e em reuniões ampliadas do Colégio de Dirigentes (CODIR). Tais ações são desenvolvidas especialmente pela Comissão de Ética e pela Corregedoria, conforme os relatos dos entrevistados.

Percebe-se, no entanto, a ausência de uma política de capacitação organizada e coordenada pelos três órgãos que formam o tripé da gestão do assédio moral na instituição. O que existe são ações esporádicas e isoladas, desenvolvidas especialmente pela Comissão de Ética e Corregedoria, quando solicitadas por algum dos campi ou por algum outro órgão de representação da instituição, como ocorreu no caso do CODIR.

As sugestões dos entrevistados para aperfeiçoar as estratégias e políticas de gestão do assédio moral no IFC foram unânimes ao propor atividades para levar informação e orientação aos servidores da instituição sobre o tema, ou seja, uma política de capacitação. Essa capacitação, conforme sugestão dos entrevistados, pode ser desenvolvida de diversas formas, como por meio de reuniões, cursos, palestras e da distribuição de materiais informativos.

A partir dessas considerações fica evidente que a instituição vem avançando na gestão do assédio moral graças à atuação de órgãos estratégicos como a Corregedoria, a Comissão de Ética e a Ouvidoria, mas precisa pensar em uma política de capacitação para todos os servidores da instituição que envolva esses três órgãos e possa ser coordenada, por exemplo, pela Diretoria de Gestão de Pessoas (DGP).

Por fim, espera-se que os resultados oriundos desta pesquisa possam contribuir para a gestão eficaz do assédio moral nas organizações públicas e privadas, mas especialmente no Instituto Federal Catarinense, que foi objeto dessa pesquisa. 


\section{REFERÊNCIAS}

BARDIN, L. Análise de conteúdo. Lisboa: Edições 70, 2006.

BRASIL. Decreto 5.480, de 30 de junho de 2005. Dispõe sobre o Sistema de Correição do Poder Executivo Federal, e dá outras providências. Brasília, DF: Presidência da República, Casa Civil, [2005]. Disponível em: http://www.planalto.gov.br/ccivil_03/_ato2004-2006/2005/decreto/d5480.htm. Acesso em: 5 dez. 2019.

BURRELL, G. Ciência normal, paradigmas, metáforas, discursos e genealogia da análise. In: CLEGG, S. R.; HARDY, C.; NORD, W. R. (org.). Handbook de estudos organizacionais: modelos de análise e novas questões em estudos organizacionais. São Paulo: Atlas, 2007. cap. 17.

CORRÊA, A. M. H.; CARRIERI, A. de P. O assédio moral degradando as relações de trabalho: um estudo de caso no Poder Judiciário. RAP - Revista de Administração Pública, Rio de Janeiro, v. 38, n. 6, p. 1065-1084, 2004. Disponível em: http://bibliotecadigital.fgv.br/ojs/index.php/rap/article/view/6771/5353. Acesso em: 3 ago. 2018.

EINARSEN, S; HOEL, H. Bullying and mistreatment at work: how managers may prevent and manage such problems. In: KINDER, A; HUGHES R.; COOPER; Cary L. (eds.). Employee well-being support: a workplace resource. New York: John Wiley and Sons Ltd, 2008. p. 161-173.

EINARSEN et al. Workplace Bullying: individual pathology or organizational culture? In: BOWIE, V.; FISCHER, B. S.; COOPER, C. L. (ed..). Workplace Violence: issues, trends, strategies. Devon: Willian Publishing, 2005. p. 229-247.

FREITAS, M. E.; HELOANI, R.; BARRETO, M. Assédio moral no trabalho. 5. ed. São Paulo: Cengage Learning, 2017.

GAULEJAC, V. Do Assédio Moral ao Assédio Social. In: SEIXAS, J.; BRESCIANI, M. S. (org.). Assédio Moral: desafios políticos, considerações sociais, incertezas jurídicas. Uberlândia, MG: EDUFU, 2006. p. 71-92.

GIL, A. C. Métodos e técnicas de pesquisa social. 6. ed. São Paulo: Atlas, 2008.

HIRIGOUYEN, M. F. Assédio moral: a violência perversa do cotidiano. 16. ed. Rio de Janeiro: Bertrand Brasil, $2017 a$.

Mal-estar no trabalho: redefinindo o assédio moral. 9. ed. Rio de Janeiro: Bertrand Brasil, 2017b.

INSTITUTO FEDERAL CATARINENSE. Plano de Integridade. Florianópolis: IFC, 2018. Disponível em: http://ifc.edu.br/wp-content/uploads/2018/06/PDFC-_ANEXO_Integridade-corrigido.pdf. Acesso em: 5 dez. 2019.

MARAZZO, L. M. et al. Assédio moral nas organizações e seus impactos. RGO - Revista Gestão Organizacional, Chapecó, v. 10, n. 1, p. 46-66, 2017. Disponível em: https://bell.unochapeco.edu.br/revistas/index.php/rgo/article/view/3605. Acesso em: 13 out. 2018.

MINAYO, M. C. S. et al. Pesquisa social: teoria, método e criatividade. 32. ed. Petrópolis, RJ: Vozes, 2008.

MOREIRA, D. A. O método fenomenológico na pesquisa. São Paulo: Pioneira Thomson, 2002.

NUNES, T. S. Assédio moral no trabalho: o contexto dos servidores da Universidade Federal de Santa Catarina. 2011. Dissertação (Mestrado em administração) - Programa de Pós-Graduação em administração da Universidade Federal de Santa Catarina, UFSC, Florianópolis, 2011. 281 p. 
NUNES, T.S.; TOLFO, S. R. Assédio moral no trabalho: consequências identificadas por servidores docentes e técnico-administrativos em uma universidade federal brasileira. Revista Gestão Universitária na América Latina - GUAL, Florianópolis, v. 5, n. 3, p. 264-286, 2012.

NUNES, T.S.; TOLFO, S. R.; NUNES, L. S. Assédio moral em universidade: a violência identificada por servidores docentes e técnico-administrativos. Organizações em contexto, São Bernardo do Campo, ISSNe 1982-8756, v. 9, n. 18, jul.-dez. 2013.

PRODANOV, C. C.; FREITAS, E. C. Metodologia do trabalho científico [recurso eletrônico]: métodos e técnicas da pesquisa e do trabalho acadêmico. 2. ed. Novo Hamburgo: Feevale, 2013.

RODRIGUES, M.; FREITAS, M. E. Assédio moral nas instituições de ensino superior: um estudo sobre as condições organizacionais que favorecem sua ocorrência. Cad. EBAPE.BR, Rio de Janeiro, v. 12, n. 2, artigo 6, abr./jun. 2014. Disponível em: http://www.scielo.br/pdf/cebape/v12n2/08.pdf. Acesso em: 17 jul. 2018.

SALIN, D. Workplace Bullying among Business Professionals: Prevalence, Organisational Antecedents and Gender Differences. Doctoral dissertation. Research Reports, Serie A, n. 117. Helsinki: Swedish School of Economics and Business Administration, 2003.

SOARES, F. C.; DUARTE, B. H. O assédio moral no ordenamento jurídico brasileiro. R. Fórum Trabalhista RFT. Belo Horizonte, ano 3, n. 11, p. 21-47, mar./abr. 2014.

VERGARA, S. C.; CALDAS, M. P. Paradigma interpretacionista: a busca da superação do objetivismo funcionalista nos anos 1980 e 1990. In: CALDAS, M.; BERTERO, C. O. (coord.). Teoria das Organizações. São Paulo: Atlas, 2007. p. 223-234. 